\title{
Comparison of subcutaneous dexmedetomidine
} versus clonidine as an adjuvant to spinal anesthesia: a randomized double blind control trial

This article was published in the following Dove Press journal:

Local and Regional Anesthesia

\author{
Divya B Srinivas' \\ Geetha Lakshminarasimhaiah ${ }^{2}$ \\ 'Department of Anaesthesiology, Sakra \\ World Hospital, Bangalore, 560 I03, India; \\ ${ }^{2}$ Department of Anaesthesiology, M.S. \\ Ramaiah Medical College and Hospitals, \\ Bengaluru, 560054, India
}

Background: Alpha-2 adrenergic agonists like clonidine and dexmedetomidine prolong the duration of postoperative analgesia and improve the quality of subarachnoid block (SAB) when used as adjuvant in various routes. However, addition of these drugs by IV or intrathecal routes are known to cause hemodynamic instability. The subcutaneous (SC) route provides similar efficacy as IV administration with less hemodynamic instability and prolonged effect.

Aims: To compare the efficacy of clonidine and dexmedetomidine as adjuvants to SAB when used subcutaneously.

Materials and methods: A total of 90 patients were randomized into one of the three groups: Group P received $1 \mathrm{ml}$ of Normal saline SC, Group D received $0.5 \mathrm{mcg} / \mathrm{kg}$ of dexmeditomedine SC and Group $\mathrm{C}$ received $1 \mathrm{mcg} / \mathrm{kg}$ of clonidine $\mathrm{SC}$ respectively after $\mathrm{SAB}$ with $3 \mathrm{ml}$ of $0.5 \%$ hyperbaric bupivacaine $(15 \mathrm{mg})$. Time of onset of sensory and motor block, intraoperative hemodynamics, postoperative VAS scores, Richmond agitation sedation scale, duration of postoperative analgesia and mean paracetamol requirement in 24 hours were recorded.

Results: Mean duration of postoperative analgesia was prolonged in group D (838.10 \pm 348.22 minutes) and group C (816.67 \pm 230.48 minutes) when compared to group P $(332.10 \pm 110.91$ minutes). Total paracetamol consumption was less in group D $(1400.00 \pm 770.13 \mathrm{mg})$ and group C (1600.00 $\pm 674.66 \mathrm{mg})$, whereas it was $1900.00 \pm 758.86 \mathrm{mg}$ in group P. Hemodynamic parameters, maximum sensory level attained, and time to attain maximum sensory levels were comparable among the two groups.

Conclusion: Both subcutaneous clonidine and dexmedetomidine prolonged the duration of postoperative analgesia and reduced analgesic requirements when used as adjuvants to $\mathrm{SAB}$ with stable hemodynamics, hence both of these drugs can be used effectively as adjuvants to SAB.

Keywords: subarachnoid block, dexmedetomidine, clonidine, postoperative analgesia

\section{Introduction}

Subarachnoid block (SAB) is a widely used regional anesthetic technique, which is a quick and effective form of regional anesthesia with predictable and reliable therapeutic benefits, and has been the technique of choice for infra-umbilical surgeries unless contraindicated. ${ }^{1,2}$ Despite these positive attributes, a major limitation of SAB is its limited duration of action. Intrathecal local anesthetics used for $\mathrm{SAB}$ is appropriate for surgeries lasting for $2-2.5$ hours. $^{2}$ Several techniques, drug regimens and additives like opioids, Alpha 2 adreno-receptor agonists have been
Correspondence: Geetha

Lakshminarasimhaiah

Department of Anaesthesiology, M.S.

Ramaiah Medical College and Hospitals,

Bengaluru 560054, India

Tel +961 1897899

Email geetha4kiran@yahoo.in 
used to eliminate anxiety, improve the quality of block and to prolong the duration of post-operative analgesia during SAB. ${ }^{1,2}$

Alpha 2 adrenergic agonists have both analgesic and sedative properties when used as adjuvants to SAB. They act at spinal and supra spinal levels of the central nervous system (CNS) to modulate pain relief.$^{3}$

Clonidine, a selective Alpha 2 adrenergic agonist has been shown to result in the prolongation of sensory and motor blockade, with reduction in the amount of local anesthetic (LA) require to produce post-operative analgesia. ${ }^{4}$ Clonidine has been effectively used as an intrathecal adjuvant to SAB with proven benefits like prolongation of duration of postoperative analgesia and improvement in the quality of SAB in many studies. ${ }^{5}$ It has also shown to have peripheral analgesic action after administration by epidural, intra venous route, wound infiltration, and topical application in various clinical studies. 6

Dexmedetomidine is a highly selective Alpha 2 adrenergic agonist; with Alpha 2/Alpha 1 selectivity ratio which is 8 to 10 times higher than clonidine, along with sympatholytic, sedative, amnestic, anxiolytic and analgesic properties. ${ }^{1,7}$ It has been shown to prolong duration of postoperative analgesia when used as an adjuvant to SAB by various routes.

Both clonidine and dexmedetomidine have been used in various routes such as oral, intrathecal, epidural, intravenous (IV), wound infiltration, intranasal routes and have been showed to prolong the duration of postoperative analgesia after $\mathrm{SAB} .^{3}$

It is a proven fact that after IV administration of drugs with a short half-life, there occurs a rapid peak in the plasma concentration, which falls rapidly resulting in short duration of action. Hence these drugs need to be administered as a continuous infusion to maintain a steady plasma concentration. $^{8}$

Subcutaneous (SC) injections have been extensively used as a route of administration for drugs with short duration of action, due to ease of administration, constant rate of drug absorption, better patient acceptance and better hemodynamic profile when compared to the IV route. ${ }^{8}$

Both clonidine and dexmedetomidine have been used as additives to bupivacaine local infiltration in various clinical studies. ${ }^{9,10}$ Dexmedetomidine has also been used as subcutaneous infusion in intensive care unit (ICU) settings for sedation $^{11}$ and as adjuvants to local anesthetics in peripheral nerve blocks. ${ }^{12}$ However there are no studies performed using alpha 2 agonists by the SC route to prolong the duration of postoperative analgesia in patients undergoing surgery under SAB.
Hence this randomized controlled trial was conducted to compare the efficacy of subcutaneous clonidine and dexmedetomidine as adjuvants to bupivacaine to prolong the duration of postoperative analgesia in patients undergoing surgeries under SAB. The secondary objectives were to assess the intraoperative hemodynamic variability, intra-operative Ramsay agitation sedation score (RASS) postoperative Visual analog scale (VAS) score and total analgesic requirement in 24 hours between the two groups.

\section{Methodology}

This prospective randomized double blind control study was conducted at Ramaiah Medical College and Hospitals, Bangalore. After obtaining institutional ethical committee clearance, 90 American Society of Anesthesiologist's Physical Status (ASA PS) I and II patients in the age group of 20-70 years scheduled to undergo elective infra-umbilical surgeries like wound debridement, ureteroscopic stenting, transurethral resection of prostate, abdominal tubectomy, and split skin grafting under subarachnoid block were recruited for the study. Sample size of 90 patients (30 patients in each group), was derived based on a previous study conducted by Reddy et $\mathrm{al}^{1}$ assuming a mean difference of 40 minutes, an alpha error of $5 \%$ with a power of $90 \%$. Patients with altered coagulation profile or bleeding diathesis, obstructive sleep apnea, pre-existing neurological deficits, surgeries in prone position, Known allergy to any of the drugs used in the study and cardiac diseases were excluded from the study.

On the previous day to surgery, after thorough preanesthetic evaluation of patients, written informed consent was obtained and they were premedicated with pantoprazole $40 \mathrm{mg}$ and ondensetron $4 \mathrm{mg}$ on the previous night. On the day of surgery, after confirming the nil per oral status patients were shifted to the operation theater, where 18 gauge IV cannula was secured and crystalloid infusion was started at a rate of $10 \mathrm{ml} /$ $\mathrm{kg}$ body weight. All standard ASA monitors like 5 lead electrocardiogram (ECG), pulse oximetry, non-invasive blood pressure monitoring (NIBP), and temperature were connected and baseline vital parameters were noted.

Under strict aseptic precautions $\mathrm{SAB}$ was performed in a sitting position after skin infiltration with $2 \%$ lignocaine in the L3-L4 space. SAB was done using 25G Quinke spinal

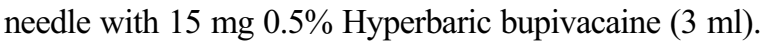

Patients were randomly allocated to groups based on computer generated random number table into three groups for subcutaneous injection (Figure 1). Group $\mathrm{C}$ received $1 \mathrm{mcg} / \mathrm{kg}$ of clonidine diluted to $1 \mathrm{ml}$ with normal saline. 
Group D received $0.5 \mathrm{mcg} / \mathrm{kg}$ of dexmedetomidine diluted to $1 \mathrm{ml}$ with NS and Group P received $1 \mathrm{ml}$ of NS. This was a randomized double blind control study.

This subcutaneous drug was prepared and injected in the forearm by a second anesthesiologist who was not involved in the study using 26 gauge $1 / 2$ inch hypodermic needle immediately following SAB. The primary anesthesiologist was unaware of the drug which was injected subcutaneously. The study data was collected and analyzed by another anesthesiologist who was not aware of the study drug injected.

All patients received supplemental oxygen via face mask at 5 liters per minute. Time of injection of the study drug was noted and vital signs were recorded at this point $(0 \mathrm{~min})$. After ensuring adequate sensory and motor blockade the surgeons were asked to proceed with the surgery.

Time of onset of maximum sensory block, time to achieve a modified bromage scale of 3 and maximum height achieved were recorded. Heart rate (HR), systolic blood pressure (SBP), diastolic blood pressure (DBP), mean arterial blood pressure (MAP), and Spo2, were recorded once every 5 minutes for the first 15 minutes and once every 15 minutes thereafter throughout the procedure.

Side effects like nausea and vomiting, hypotension (fall in MAP by more than $20 \%$ from baseline) and bradycardia (HR less than 50 beats per minute or decrease more than $20 \%$ from baseline) were noted and treated with Ondensatron $4 \mathrm{mg}$ IV, Ephedrine $6 \mathrm{mg}$ boluses and atropine $0.6 \mathrm{mg}$ IV respectively.

After the surgery, patients were monitored in the Post anesthesia care unit (PACU) for vitals like

$\mathrm{HR}, \mathrm{BP}, \mathrm{RR}$ and $\mathrm{SpO} 2$ every 15 minutes. The VAS (Visual Analogue Scale) score was used to assess pain at 0, 4, 8, 12, 16, 20, 24 hours postoperatively. Inj Paracetamol 1 gm IV was given as first rescue analgesic on patients request or if VAS $>4$ and repeated thereafter on patients request. Time for request of first rescue analgesic and total analgesic requirement in 24 hours was recorded.

\section{Statistical analysis}

Descriptive and inferential statistical analysis were carried out in the present study. Results on continuous measurements are presented as Mean $\pm \mathrm{SD}$ (Min-Max) and results on categorical measurements are presented in Number (\%). Significance is assessed at $5 \%$ level of significance. The following assumptions on data were made 1) Dependent variables should be normally distributed; and 2) Samples drawn from the population should be random, cases of the samples should be independent

Statistical analysis was performed using Analysis of variance (ANOVA) to find the significance of study parameters between three or more groups of patients. Post-hoc Tukey (two-tailed, independent) was used to find the significance of study parameters on a continuous scale between two groups (Inter-group analysis) on metric parameters. Chi-square or Fisher Exact test was used to find the significance of the study parameters on a categorical scale between two or more groups, nonparametric setting for qualitative data analysis. The Fisher exact test was used when cell samples were very small. SPSS 18.0 was used for the analysis of the data (IBM Corporation, Armonk, NY, USA).

\section{Ethics statement}

We confirm that this study was approved by Ramaiah Medical College and Hospitals Ethics Committee, Bengaluru 560054. This study was conducted in accordance with the Declaration of Helsinki throughout the project.

\section{Results}

All demographic variables like age, gender, BMI, ASA physical status, duration of surgery were identical among

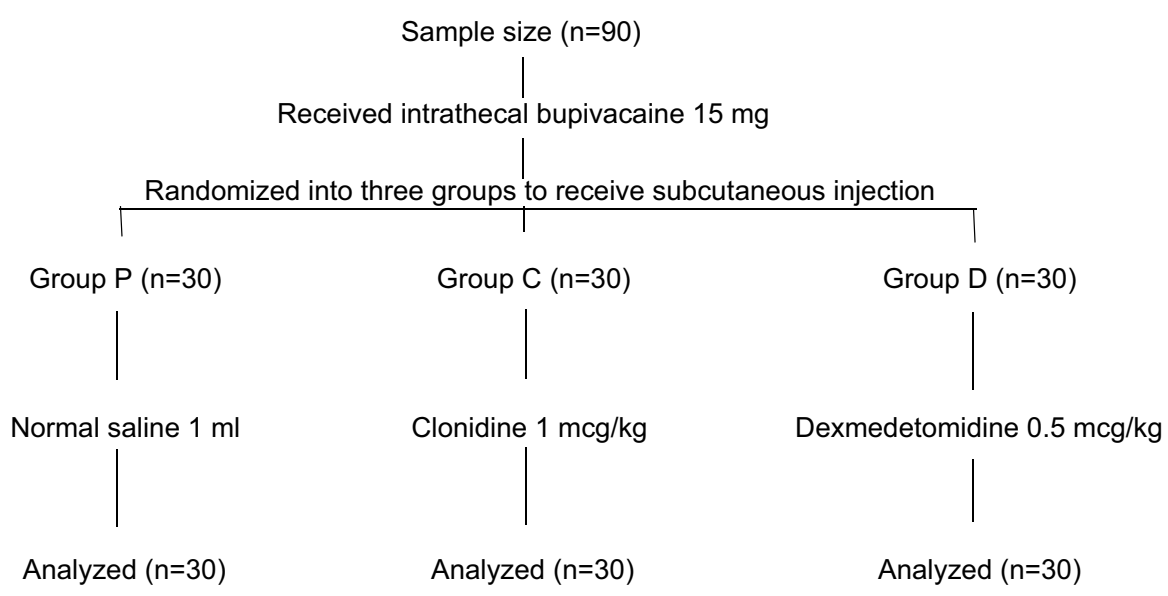

Figure I Flow chart of the study. 
Table I Comparison of demographic variables

\begin{tabular}{|c|c|c|c|c|c|c|}
\hline Age & \multicolumn{2}{|c|}{ Group P } & \multicolumn{2}{|l|}{ Group D } & \multicolumn{2}{|c|}{ Group C } \\
\hline Mean $\pm S D$ & \multicolumn{2}{|c|}{$39.97 \pm 11.89$} & \multicolumn{2}{|l|}{$42.10 \pm 11.98$} & \multicolumn{2}{|c|}{$39.10 \pm 12.40$} \\
\hline Gender & \multicolumn{2}{|c|}{ Group P } & \multicolumn{2}{|l|}{ Group D } & \multicolumn{2}{|c|}{ Group C } \\
\hline & No & $\%$ & No & $\%$ & No & $\%$ \\
\hline Female & 14 & 46.17 & 14 & 46.17 & 12 & 40 \\
\hline Male & 16 & 53.3 & 16 & 53.3 & 18 & 60 \\
\hline ASA Grade & \multicolumn{2}{|c|}{ Group P } & \multicolumn{2}{|l|}{ Group D } & \multicolumn{2}{|c|}{ Group C } \\
\hline & No & $\%$ & No & $\%$ & No & $\%$ \\
\hline Grade I & 17 & 56.7 & 17 & 56.7 & 18 & 60 \\
\hline Grade II & 13 & 43.3 & 13 & 43.3 & 12 & 40 \\
\hline Surgery Duration (min) & \multicolumn{2}{|c|}{ Group P } & \multicolumn{2}{|l|}{ Group D } & \multicolumn{2}{|c|}{ Group C } \\
\hline & No & $\%$ & No & $\%$ & No & $\%$ \\
\hline$<60$ & 13 & 43.3 & 8 & 26.7 & 14 & 46.7 \\
\hline $60-100$ & 14 & 46.7 & 15 & 50 & 11 & 36.7 \\
\hline$>100$ & 3 & 10 & 7 & 23.3 & 5 & 16.7 \\
\hline \multirow[t]{2}{*}{ Mean $\pm S D$} & \multicolumn{2}{|c|}{$60.00 \pm 26.42$} & \multicolumn{2}{|l|}{$70.50 \pm 31.30$} & \multicolumn{2}{|c|}{$61.00 \pm 30.50$} \\
\hline & \multicolumn{2}{|c|}{ Group P } & Group D & Group C & \multicolumn{2}{|c|}{$P$-value } \\
\hline Height $(\mathrm{cm})$ & \multicolumn{2}{|c|}{$162.60 \pm 6.30$} & $164.10 \pm 5.86$ & $161.27 \pm 5.72$ & \multicolumn{2}{|c|}{0.190} \\
\hline Weight (kg) & \multicolumn{2}{|c|}{$64.10 \pm 6.81$} & $65.57 \pm 8.39$ & $64.90 \pm 8.72$ & \multicolumn{2}{|c|}{0.778} \\
\hline BMI $\left(\mathrm{kg} / \mathrm{m}^{2}\right)$ & \multicolumn{2}{|c|}{$24.26 \pm 2.40$} & $24.30 \pm 2.48$ & $24.91 \pm 2.69$ & \multicolumn{2}{|c|}{0.535} \\
\hline
\end{tabular}

Notes: Group C,received I mcg/kg of clonidine diluted to I ml with normal saline; Group D received $0.5 \mathrm{mcg} / \mathrm{kg}$ of dexmedetomidine diluted to I ml with NS and Group P (placebo) received $\mathrm{I} \mathrm{ml}$ of $\mathrm{NS}$.

Table 2 Maximum sensory level attained

\begin{tabular}{|l|l|l|l|l|l|l|l|}
\hline & \multicolumn{2}{|l|}{ Group P } & \multicolumn{2}{l|}{ Group D } & \multicolumn{2}{l|}{ Group C } & \\
\hline $\begin{array}{l}\text { Max sen- } \\
\text { sory level }\end{array}$ & No & $\%$ & No & $\%$ & No & $\%$ & P-value \\
\hline T6 & 8 & 26.7 & 9 & 30 & 6 & 20 & 0.267 \\
T8 & 9 & 30 & 14 & 46.7 & 8 & 26.7 & \\
T10 & 10 & 33.3 & 7 & 23.3 & 13 & 43.3 & \\
T12 & 3 & 10 & 0 & 0 & 3 & 10 & \\
\hline
\end{tabular}

Notes: Group C,received I $\mathrm{mcg} / \mathrm{kg}$ of clonidine diluted to I $\mathrm{ml}$ with normal saline; Group D received $0.5 \mathrm{mcg} / \mathrm{kg}$ of dexmedetomidine diluted to $1 \mathrm{ml}$ with NS and Group P (placebo) received I $\mathrm{ml}$ of NS.

all the three groups (Table 1). We did not find any statistical significance in the maximum sensory level reached between the groups although group D achieved higher sensory level (Table 2) compared to the other two groups.

The results of the study showed a statistically significant difference in the post-operative VAS score, the time to first request of post-operative analgesia and mean paracetamol consumption among the three groups.
Postoperative VAS scores (Table 3) were significantly higher in group $\mathrm{P}$ for first 12 hours postoperatively when compared to group D and group C. Patients in group D had lower VAS scores throughout the 24-hour period, the lowest value being at 4 hours $(2.47 \pm 0.90)$ and in group $C$ it was 2.67 \pm 0.55 which had high statistical significance. $P$-value was $<0.05$ up to 12 hours post operatively between group $\mathrm{P}$ and group $\mathrm{D}$ and also between group $\mathrm{P}$ and group C. However there was no statistical significant difference between group $\mathrm{D}$ and group $\mathrm{P}$.

The mean duration of postoperative analgesia, defined by the time for use of first rescue analgesic (Figure 2) was $332 \pm 110.91$ minutes in group $P$, $838.10 \pm 348.22$ minutes in group D and $816.67 \pm 230.48$ minutes in group $\mathrm{C}$. This difference was statistically significant with a $P$-value $<0.001$.

The mean paracetamol consumption (Figure 3) in group $\mathrm{P}$ was $1900 \pm 758.86 \mathrm{mg}$, group D $1400 \pm 770.13 \mathrm{mg}$ and patients in group C $1600 \pm 674.66 \mathrm{mg}$. The results suggest that patients in group $P$ required higher doses of paracetamol for 
Table 3 Postoperative VAS score

\begin{tabular}{|l|l|l|l|l|l|l|}
\hline \multirow{2}{*}{ Post op VAS } & \multicolumn{2}{|l}{ Results } & \multicolumn{2}{l|}{ Group Wise P-value } \\
\cline { 2 - 7 } & Group P & Group D & Group C & Group P-D & Group P-C & Group D-C \\
\hline $0 \mathrm{hrs}$ & $0.00 \pm 0.00$ & $0.00 \pm 0.00$ & $0.00 \pm 0.00$ & - & - & - \\
$4 \mathrm{hrs}$ & $3.77 \pm 1.25$ & $2.47 \pm 0.90$ & $2.67 \pm 0.55$ & $<0.00 I^{* *}$ & $<0.00 I^{* *}$ & $0.69 \mathrm{l}$ \\
$8 \mathrm{hrs}$ & $3.37 \pm 0.72$ & $2.80 \pm 0.76$ & $3.00 \pm 0.95$ & $0.023^{*}$ & 0.195 & 0.610 \\
$12 \mathrm{hrs}$ & $3.97 \pm 1.22$ & $3.10 \pm 0.80$ & $3.27 \pm 1.14$ & $0.007^{* *}$ & $0.035^{*}$ & 0.819 \\
$16 \mathrm{hrs}$ & $3.67 \pm 0.88$ & $3.60 \pm 1.13$ & $3.43 \pm 0.97$ & 0.964 & 0.640 & 0.796 \\
$20 \mathrm{hrs}$ & $3.33 \pm 0.88$ & $3.67 \pm 1.18$ & $3.60 \pm 1.04$ & 0.434 & 0.585 & 0.967 \\
$24 \mathrm{hrs}$ & $3.43 \pm 0.73$ & $3.40 \pm 0.77$ & $3.30 \pm 0.75$ & 0.984 & $0.77 \mathrm{I}$ & 0.863 \\
\hline
\end{tabular}

Notes: Group C, received I mcg/kg of clonidine diluted to I $\mathrm{ml}$ with normal saline; Group D received $0.5 \mathrm{mcg} / \mathrm{kg}$ of dexmedetomidine diluted to I ml with NS and Group P (placebo) received I $\mathrm{ml}$ of $\mathrm{NS}$. $* P \leq 0.05 ; * * P \leq 0.01$

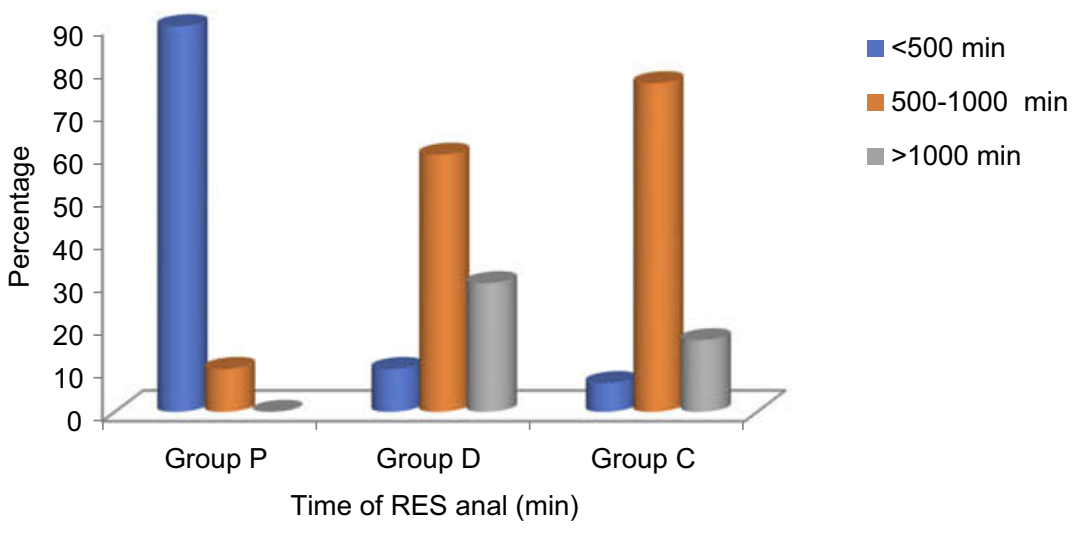

Figure 2 Time for first rescue analgesia.

Notes: Group C, received I mcg/kg of clonidine diluted to I ml with normal saline; Group D received $0.5 \mathrm{mcg} / \mathrm{kg}$ of dexmedetomidine diluted to I ml with NS and Group P (placebo) received I $\mathrm{ml}$ of NS.

Abbreviation: RES, rescue.

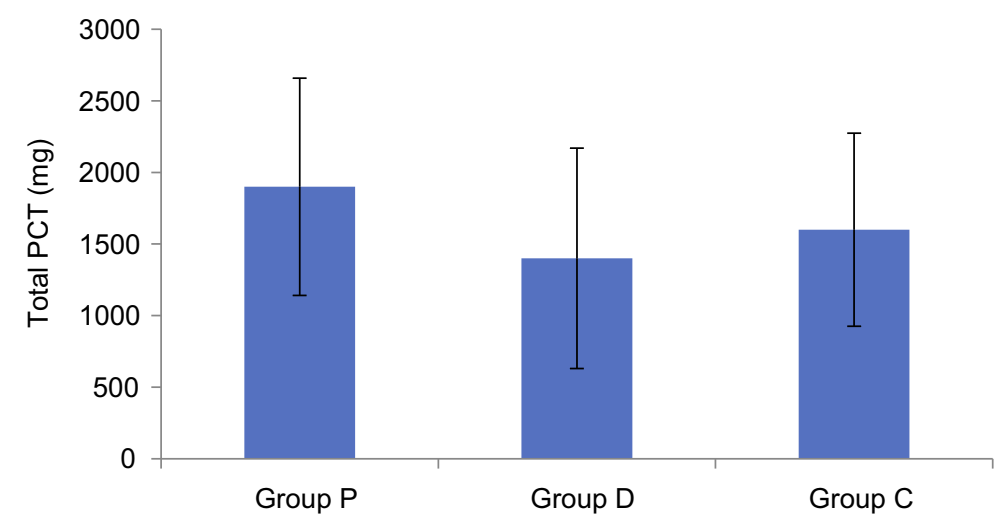

Figure 3 Comparison of mean PCT consumption.

Notes: Group C,received I mcg/ $/ \mathrm{kg}$ of clonidine diluted to I $\mathrm{ml}$ with normal saline; Group D received $0.5 \mathrm{mcg} / \mathrm{kg}$ of dexmedetomidine diluted to I ml with NS and Group P (placebo) received I $\mathrm{ml}$ of $\mathrm{NS}$.

Abbreviation: PCT-Paracetamol

postoperative analgesia when compared to group $\mathrm{D}$ and group

$\mathrm{C}$ and this difference was statistically significant with a $P$-value of 0.034 .
Time to achieve Bromage scale 3 in group $\mathrm{C}$ was $3.43 \pm 1.30$ minutes, in group D $4.03 \pm 2.53$ minutes and group P, $4.30 \pm 2.07$ minutes, with a $P$-value of $<0.05$ and 


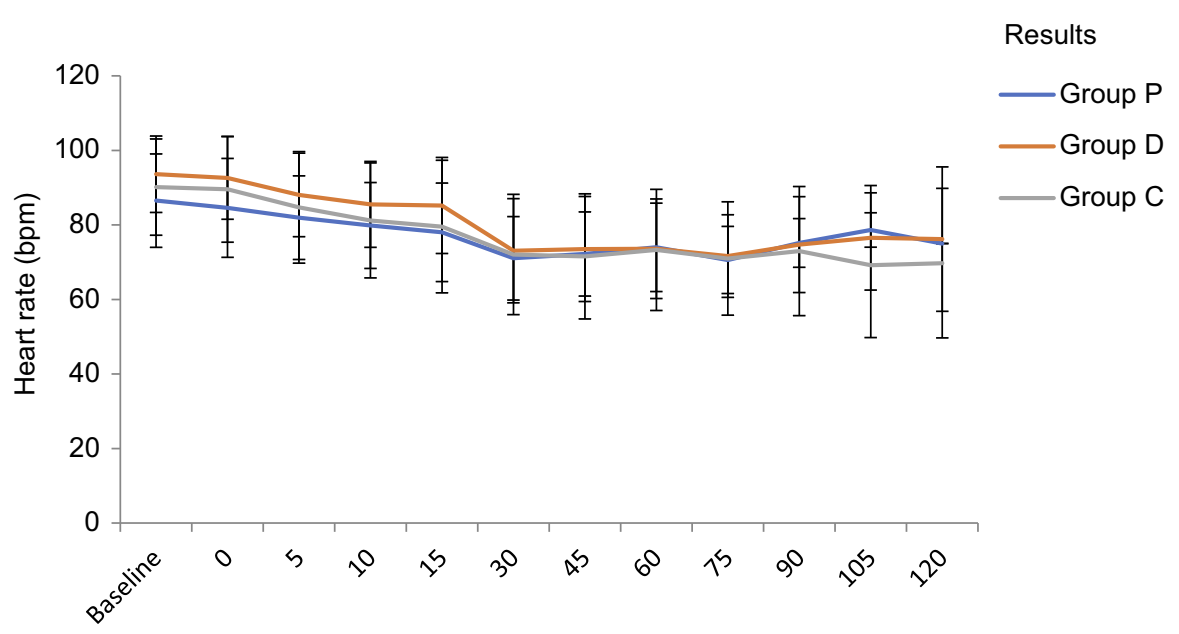

Figure 4 Comparison of intraoperative heart rate.

Notes: Group C,received I mcg/kg of clonidine diluted to I ml with normal saline; Group D received $0.5 \mathrm{mcg} / \mathrm{kg}$ of dexmedetomidine diluted to I $\mathrm{ml}$ with NS and Group P (placebo) received I $\mathrm{ml}$ of NS.

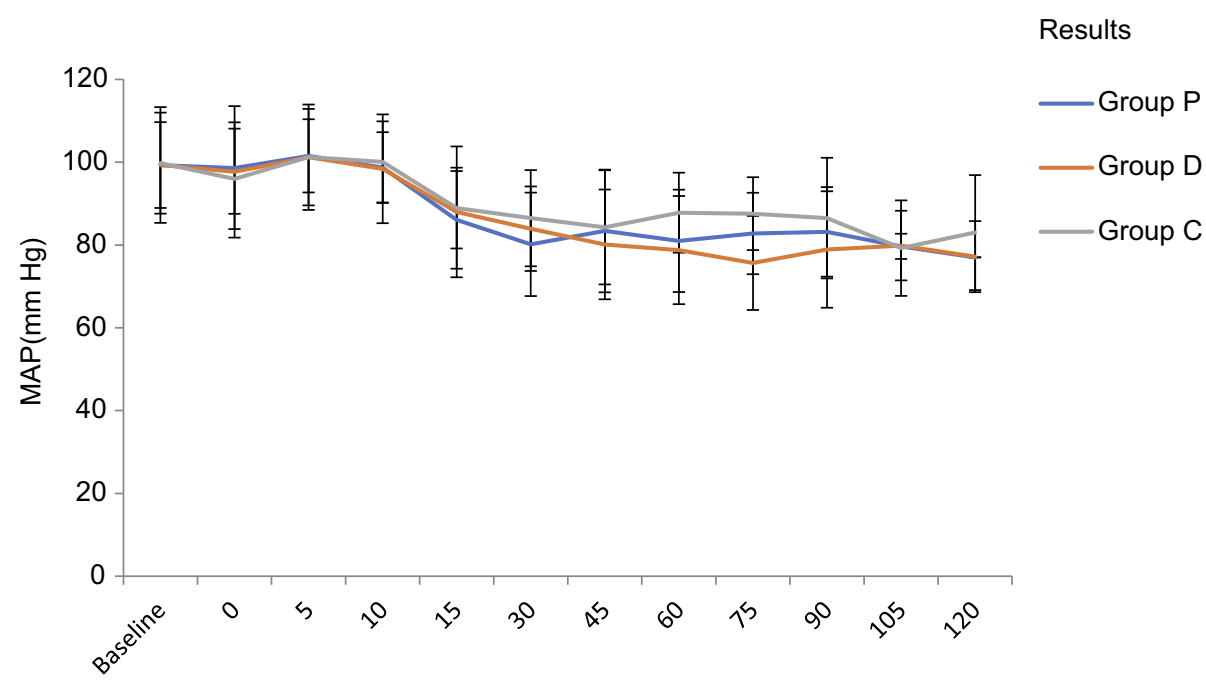

Figure 5 MAP comparison among three groups.

Notes: Group C,received I mcg/ $/ \mathrm{kg}$ of clonidine diluted to I ml with normal saline; Group D received $0.5 \mathrm{mcg} / \mathrm{kg}$ of dexmedetomidine diluted to I $\mathrm{ml}$ with NS and Group P (placebo) received I $\mathrm{ml}$ of $\mathrm{NS}$.

Abbreviation: MAP, mean arterial pressure.

mean time to attain the highest sensory level of T6 was $5.57 \pm 2.31$ minutes in group $\mathrm{P}, 5.70 \pm 2.72$ minutes in group D and $5.37 \pm 2.33$ minutes in group C. Other parameters like time to achieve maximum sensory level, and Bromage scale, and hemodynamic parameters were identical among the three study groups.

It is seen that the Heart rate and MAP (Figures 4 and 5) were comparable among the three groups at all times except at 75 and 90 minutes during which patients who received dexmedetomidine had a lower MAP in comparison to the other two groups and this difference was statistically significant.

\section{Discussion}

In our study, the primary objective was to assess the mean duration of postoperative analgesia, which was $332 . \pm 110.91$ minutes in group P, 838.10 \pm 348.22 minutes in group D and $816.67 \pm 230.48$ minutes in group $\mathrm{C}$. The results were comparable to that of a study conducted by Reddy et al $^{1}$ to compare the efficacy of IV dexmedetomidine and clonidine premedication during SAB which prolonged the duration of postoperative analgesia to $243.35 \pm 56.82$ minutes and $190.93 \pm 43.38$ minutes. Harsoor et $\mathrm{al}^{2}$ also obtained similar results in their study, where they compared IV dexmedetomidine 
infusion and placebo for patients undergoing surgery under bupivacaine spinal anesthesia. Supplementation of IV dexmedetomidine infusion along with SAB prolonged the duration of postoperative analgesia in group $\mathrm{D}$ to $222.8 \pm 123.4$ minutes, where as it was 138.36 \pm 21.62 minutes in group $\mathrm{C}$.

Patients who received SC dexmedetomidine or clonidine as adjuvants to $\mathrm{SAB}$ required significantly less analgesia in the postoperative period in contrast to patients who received $\mathrm{SAB}$ alone. Agarwal et $\mathrm{al}^{3}$ compared IV dexmedetomidine infusion versus IV clonidine infusion as adjuvant to SAB. They found that patients who received either of the two drugs intraoperatively required significantly lower doses of rescue analgesic agents in the postoperative period when compared to the control group.

The hemodynamics in any of the patients HR, SBP, DBP, and MAP among patients receiving either dexmedetomidine or clonidine was comparable to the placebo group without incidence of significant bradycardia and hypotension.

We did not find any improvement in the onset times of sensory and motor blockade with the use of SC alpha 2 agonists, in contrast to previous studies which used IV alpha 2 agonists. This could be because the slower rate of absorption of subcutaneously administered drugs, which results in a slow rise in plasma concentration of the drug in contrast to the IV route thereby resulting in much less hemodynamic instability and prolonged duration of analgesia could be attributed to the longer half life of subcutaneously administered drugs. However the study has a few limitations in that it was performed in a small group and the regression time of sensory and motor block was not assessed. Comparison of the IV and SC routes of a single drug (either dexmedetomidine or clonidine) gave a better idea about the pharmacodynamics and pharmacokinetics of the drugs.

\section{Conclusion}

Both dexmedetomidine and clonidine can be used safely and effectively bythe SCroute as adjuvants to SAB, to prolong the duration of analgesia. When used by the SC route, these adjuvants provide much more stable hemodynamic parameters than IV administration. However, among the two drugs, dexmedetomidine would provide a longer duration of analgesia along with intraoperative sedation than clonidine. This being the first study using subcutaneous alpha 2 agonists as adjuvants for prolongation of duration of postoperative analgesia, the results of the study cannot be generalized. Further studies with larger sample sizes would be required to prove the efficacy of SC alpha 2 agonists as adjuvants to SAB. The future studies with additional analysis of regression time of sensory and motor block following SC use of these agents are advisable.

\section{Disclosure}

The authors report no conflicts of interest in this work.

\section{References}

1. Reddy VS, Shaik NA, Donthu B, Sannala VKR, Jangam V. Intravenous dexmedetomidine versus clonidine for prolongation of bupivacaine spinal anesthesia and analgesia: a randomized double-blind study. J Anaesthesiol Clin Pharmacol. 2013;29:342-347. doi:10.4103/09709185.117101

2. Harsoor S, Rani D, Yalamuru B, Sudheesh K, Nethra SS. Effect of supplementation of low dose intravenous dexmedetomidine on characteristics of spinal anaesthesia with hyperbaric bupivacaine. Indian J Anaesth. 2013;57:265-269. doi:10.4103/0019-5049.115616

3. Agrawal A, Agrawal S, Payal YS. Comparison of block characteristics of spinal anesthesia following intravenous dexmedetomidine and clonidine. J Anaesthesiol Clin Pharmacol. 2016;32:339-343. doi:10.4103/0970-9185.188830

4. Dinesh CN, Tej NS, Yatish B, Pujari VS, Kumar RM, Mohan CV. Effects of intravenous dexmedetomidine on hyperbaric bupivacaine spinal anesthesia: a randomized study. Saudi J Anaesth. 2014;8:202-208. doi:10.4103/1658-354X.130719

5. Mahendru V, Tewari A, Katyal S, Grewal A, Singh MR, Katyal R. A comparison of intrathecal dexmedetomidine, clonidine and fentanyl as adjuvants to hyperbaric bupivacaine for lower limb surgery: a double blind controlled study. J Anaesthesiol Clin Pharmacol. 2013;29:496-502. doi:10.4103/0970-9185.119151

6. Bharti N, Dontukurthy S, Bala I, Singh G. Postoperative analgesic effect of intravenous (i.v) clonidine compared with clonidine administration in wound infiltration for open cholecystectomy. $\mathrm{Br}$ $J$ Anaesth. 2013;111:656-661. doi:10.1093/bja/aet130

7. Afonso J, Reis F. Dexmedetomidine: current role in anesthesia and intensive care. Rev Bras Anesthesiol. 2012;62:118-133. doi:10.1016/ S0034-7094(12)70110-1

8. McLennan DN, Porter CJH, Charman SA. Subcutaneous drug delivery and the role of the lymphatics. Drug Disco Today Technol. 2005;2 (1):89-96. Spring. DOI:10.1016/j.ddtec.2005.05.006

9. Nataraj MS, Mohan Kumar RM. Effect of clonidine as an adjuvant for wound infiltration following caesarean section. J Obstet Anesth Crit Care. 2017;7:33-36. doi:10.4103/2249-4472.207389

10. Singh S, Prasad C. Post-operative analgesic effect of dexmedetomidine administration in wound infiltration for abdominal hysterectomy: a randomized control study. Indian J Anaesth. 2017;61:52-56. doi:10.4103/ija.IJA_676_16

11. Gertler R, Brown HC, Mitchell DH, Silvius EN. Dexmedetomdine: a novel sedativeanalgesia agent. BUMC Proceedings. 2001;14:13-21.

12. Swami S, Keniya VM, Ladi SD, Rao R. Comparison of dexmedetomidine and clonidine (alpha2 agoinst drugs) as an adjuvant to local anaesthesia in supraclavicular brachial plexus block: a randomized double-blind prospective study. Indian J Anaesth. 2012;56:243-249. doi:10.4103/0019-5049.98767 


\section{Publish your work in this journal}

Local and Regional Anesthesia is an international, peer-reviewed, open access journal publishing on the development, pharmacology, delivery and targeting and clinical use of local and regional anesthetics and analgesics. The journal welcomes submitted papers covering original research, basic science, clinical studies, reviews \&

evaluations, guidelines, expert opinion and commentary, case reports and extended reports. The manuscript management system is completely online and includes a very quick and fair peer-review system, which is all easy to use. Visit http://www.dovepress.com/testimonials. php to read real quotes from published authors.

Submit your manuscript here: https://www.dovepress.com/local-and-regional-anesthesia-journal 